\title{
Dactylogyrus fraternus Wagener, 1909 (Monogenea: Dactylogyridae) Parasitic on Alburnus alburnus (Cyprinidae) from Turkey
}

\author{
Mustafa KOYUN ${ }^{1)}$, Faik Naci ALTUNEL ${ }^{2)}$ \\ ${ }^{1)}$ Bingol University, Science and Art Faculty, Department of Biology-Zoology, 12000 Bingol, Turkey; mustafakoyun16@yahoo.com \\ ${ }^{2)}$ Uludag University, Science and Art Faculty, Department of Biology-Zoology, 16000 Bursa, Turkey; altunel@uludag.edu.tr
}

\begin{abstract}
Dactylogyrus species are a group of monogenean gill parasites that are highly specific to freshwater fishes; represents the most dominant genus among the Monogenea with regard to host distribution and location. They were sampled 14 species from more than 27 host collected in Turkey. Among these dactylogyrid parasites, Dactylogyrus fraternus could be described and illustrated from specimens collected from gills of a cyprinid fish, bleak Alburnus alburnus, in Enne Dam reservoir from Kutahya, Turkey. Diagnostic characters of this species are the tegument of trunk showing annulations, except on the cephalic region, and copulatory complex comprising sclerotized, basal part broad, the tube which is long and hard. The purpose of the present study was to determine, on the whole, the body structure of the Dactylogyrus fraternus in bleak.
\end{abstract}

Keywords: Monogenea, Dactylogyridae, Dactylogyrus fraternus, Alburnus alburnus

\section{Introduction}

Monogeneans are almost entirely dependent upon their hosts, which constitute their sole environment throughout the life cycle, and they are known to be generally highly host-specific (Baer, 1957; Kennedy, 1975; Rohde, 1979, Noble et al., 1989; Sasal et al., 1998). They are flatworms (Platybelminthes), ectoparasitic which attach on their host's skin or gills by special attachment organs, posterior positioned (Park et al., 2007). Monogeneans, possibly with a few exceptions, have direct life cycles, without intermediate hosts (Reichenbach-Klinke, 1973 ).

The adult worm infecting a vertebrate host lays eggs from which ciliated larvae (oncomiracidia) hatch to infect vertebrates, usually of the same species. Larvae may be free swimming or hatch only once the eggs have established contact with the host. Each egg develops to a single adult worm which produces many eggs during its life. Their anterior end contains apical sensory structures, a mouth with or without accessory suckers and special glands or clamps for attachment. All are hermaphrodite; the testis is single or follicular; sperm is evacuated into a specialized, often sclerotinized copulatory organ. Female organs include an ovary and follicular vitelline glands. The uterus usually contains no more than one, or only a few eggs (Hayward, 2005; Whittington, 2005).

Dactylogyroidae are 300-2000 $\mu \mathrm{m}$ long and usually have one or two anterior-dorsal pairs of eyes and a posteriorventral attachment organ (the opisthaptor). This disk-like organ contains centrally positioned sclerotinoid anchors, connected to support bars and marginally located hooklets. Most dactylogyroids are gill parasites and only a few are skin parasites, among which most notably is Gyrodac- tylidae (Ergens, 1988). All remaining Dactylogyroidae are oviparous with prominent vitelline follicles, usually with one to two pairs of pigmented eyes, the anchor only loosely connected (through ligaments) with the bars (Rohde et al., 1989). The objective of this study was to determine the anatomical structure and the details for identifying $D$. fraternus were studied.

\section{Materials and methods}

The Monogeneans studied are a part of the material collected from 972 specimens of the bleak Alburnus alburnus (Linnaeus, 1758) from Enne Dam Reservoir of Kutahya state of Turkey from February 1998 to January 2000. The monogeneans were removed from the gills of hosts with a 1:4000 formaldehyde solution, fixed in 5\% formaldehyde and stored in $70 \%$ ethanol. The parasites were stained with iron-aceto-carmine mounted in glycerin-jell and some specimens were mounted for the study of sclerotized structures. All the measurements are micrometers $(\mu \mathrm{m})$ in the text; the mean is followed by the range and the number of specimens measured $(\mathrm{n})$ in parentheses. The illustrations were made with the aid of a drawing tube mounted on a phase contrast microscope. The numeration of the hook pairs follows (Mizelle, 1936).

\section{Results and discussion}

Dactylogyrus fraternus Wagener, 1909

Description: (based on 30 specimens)

D. fraternus has the body $356 \mu \mathrm{m}(348-360, \mathrm{n}=30)$ long, greatest width $70 \mu \mathrm{m}(60-72, \mathrm{n}=30)$. Has cephalic lobes developed, 3 pairs of head organs. Accessory eye 
granules oval, not scattered in cephalic area. The pharynx is oval, and has $24 \mu \mathrm{m}(18-26, \mathrm{n}=13)$ in diameter; the esophagus is elongate; same the peduncle is elongate. The haptor is sub hexagonal, $74 \mu \mathrm{m}(68-81, \mathrm{n}=30)$ long, 138 $\mu \mathrm{m}(96-153, \mathrm{n}=30)$ wide. The anchors are similar.

Anchors (Fig. 2) a: 32 (30-34, n = 9), b: 29 (27-31, n = 9), c: $27(24-29, \mathrm{n}=9), \mathrm{d}: 3(2-5, \mathrm{n}=9)$, e: $13(9-15$, $n=9), f: 9(7-13, n=9), g: 11(9-13, n=9)$, h: $27(25-$ $31, \mathrm{n}=9) \mu \mathrm{m}$ wide; with elongate superficial root, short broad deep root, curved shaft, recurved point and anchor filaments.

Ventral bar (Fig. 1-4) $16(14-18, n=9)$ long, plate-like, with slightly enlarged ends and medial ridge; dorsal bar; (Fig. 1-3) $20(18-22, \mathrm{n}=9)$ long, medial bend.

Hooks similar; each with erect thumb, shaft and evenly curved point; proximal half of shank dilated. Hook pairs: A; (Fig. 1-7; Fig. 1-8) a: region of point; $5(3-8, n=9)$, b: superficial root; $8(4-10, \mathrm{n}=9)$, c: base and shaft; 11 $(7-14, \mathrm{n}=9)$ long, $\mathrm{B}$; a: region of point; $8(5-12, \mathrm{n}=9)$, b: superficial root; $12(7-16, \mathrm{n}=9)$, c: base and shaft; 37 $(31-43, n=9)$ long, C; a: region of point; $6(3-8, n=9)$, b: superficial root; $9(7-11, \mathrm{n}=9)$, c: base and shaft; 21 $(17-25, n=9)$ long, $D ;$ a: region of point; $9(6-12, n=9)$, b: superficial root; $11(8-15, \mathrm{n}=9)$, c: base and shaft; 17
$(13-20, n=9)$ long. Male copulatory organ; sclerotized an elongated tube with broad basal part (Fig. 1-5) 32 (30-36, $\mathrm{n}=9)$ wide, the tube is long and hard structure, $18(16-20$, $\mathrm{n}=9)$ wide, with variable flattened projection near midlength. Testis is oval shape ventral to Ovarium, 22 (20-24, $\mathrm{n}=9$ ) long; vas deferens elongate; seminal vesicle developed, suboval; two saccate prostatic reservoirs. Ovarium elongate, 39 (36-40, $n=9)$ long, $23(22-24, n=9)$ wide. Vitellaria lateral. Uterus and eggs were not observed.

Dactylogyroidea is based on structural variation in the sclerotinoid attachment organs in the opisthaptor (for the generic division) and of the sclerotinoid copulatory organ (for specific differentiation). Specific differentiation of monogeneans other than Dactylogyridae requires consideration of a wider range of morphological and anatomical characters (Bykhowski, 1957; Paperna, 1979).

$D$. fraternus is found during the current study is considered new locality record on $A$. alburnus, which was the most abundant fish caught in the dam reservoir. In several studies, it has been shown that $D$. alatus and $D$. fraternus are specific parasites for the genus Alburnus (Hargis, 1957; Lambert, 1977; Dupond and Lambert,1986; Gelnar et al., 1994).
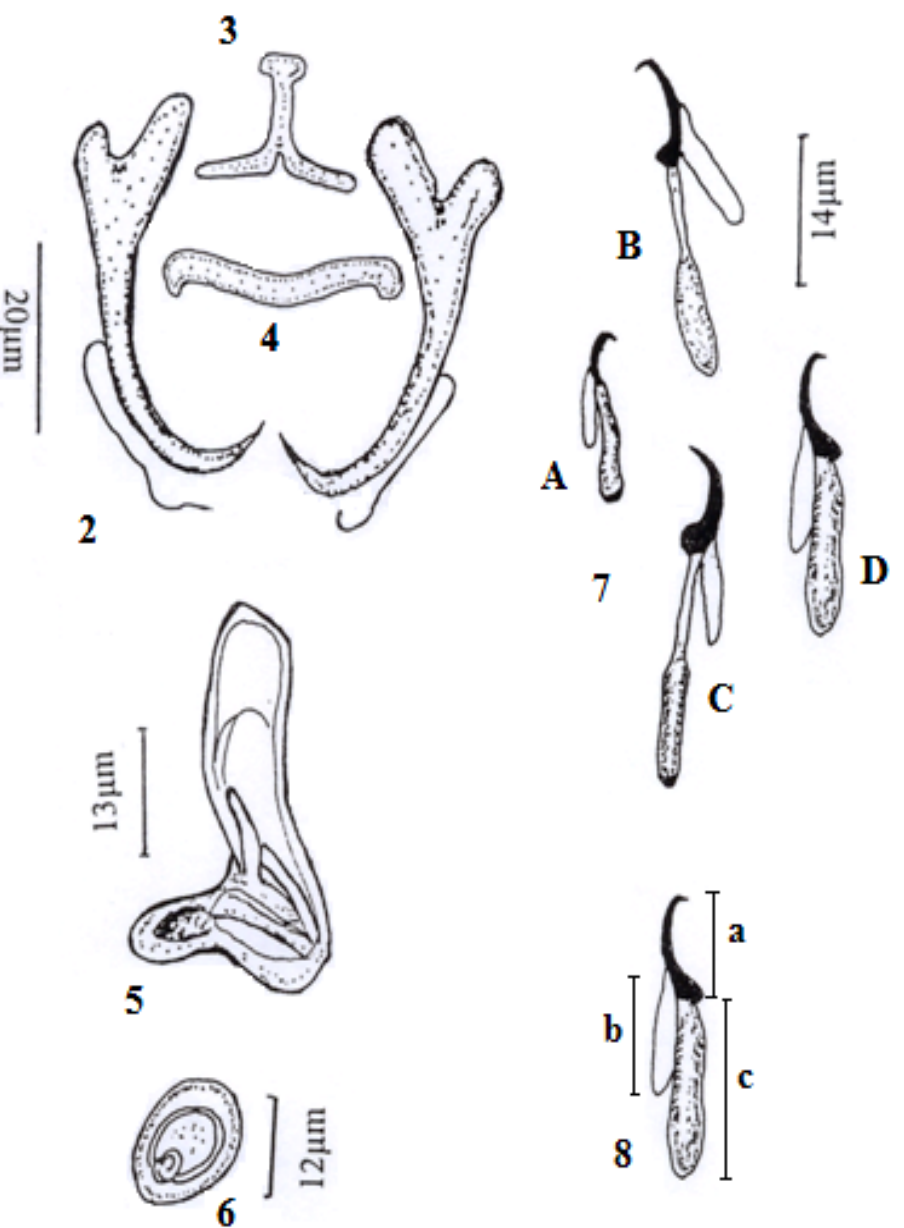

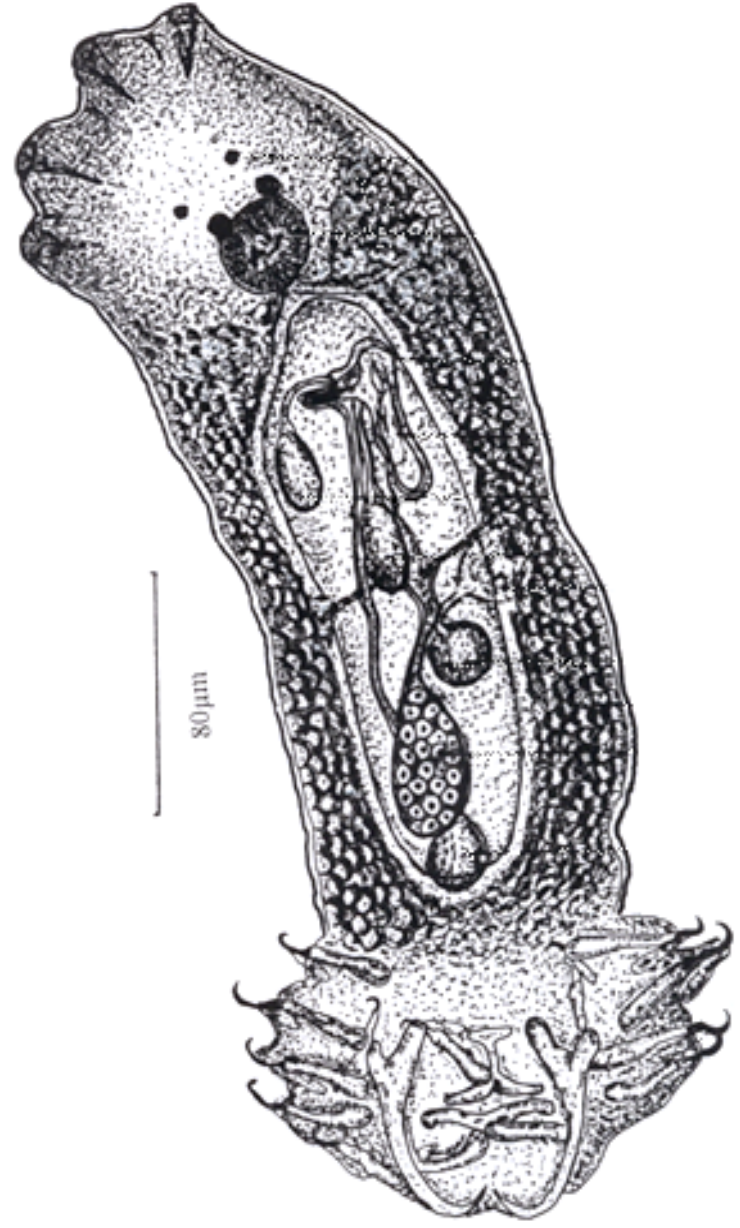

Fig. 1. Dactylogyrus fraternus composite drawing of whole mount (ventral view); 2. Anchors; 3. Dorsal bar; 4. Ventral bar; 5. Copulatoty organ; 6. Vagina; 7. A - B -C - D marginal hook pairs; 7. a: region of point, b: superficial root, c: base and shaft; 8 . Marginal hook scale (2-8 drawn to different) 


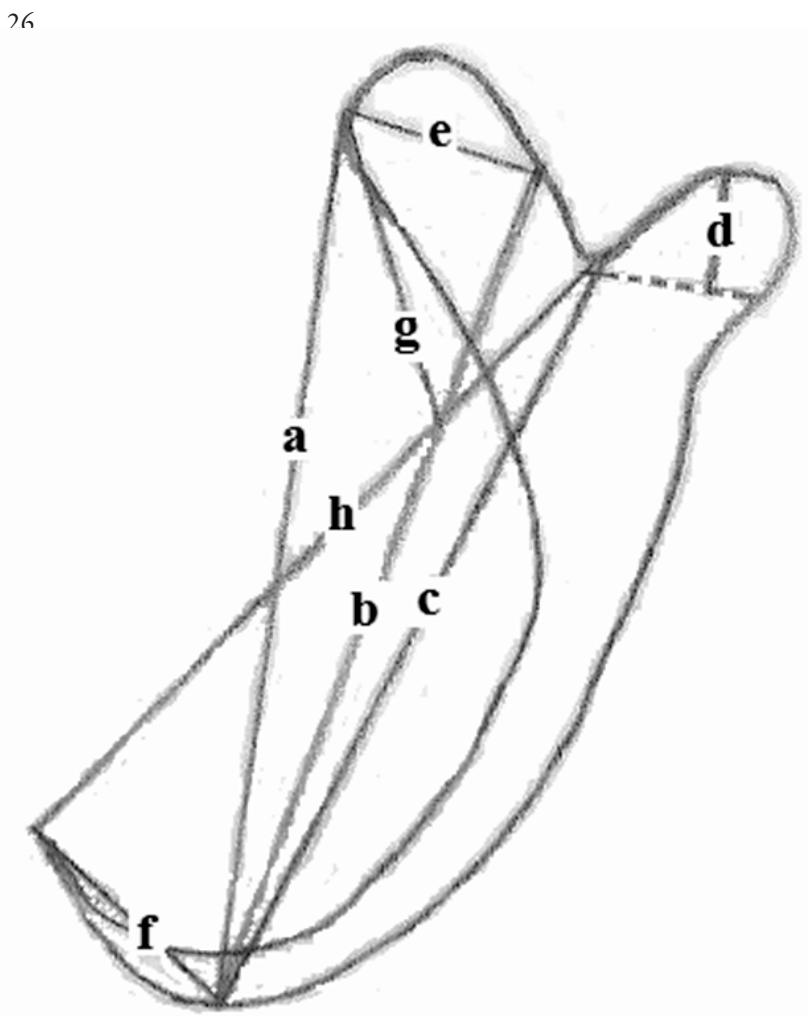

Fig. 2. Measurements of the ancors of Dactylogyrus fraternus; (a) overall length; (b) length of the anchors without foldable part of the internal process; (c) length of the base; (d) length of the external process; (e) length of the foldable part of the internal process; (f) length of the internal process; ( $g$ ) length of the foldable part of the internal process; ( $h$ ) width of the anchor

\section{Conclusions}

In the current study the anatomical structure of this parasite and the shape of its haptor and metric properties were studied. The aim of the study provide deatiled drawings and measurments of the taxonomically important structures-the complex of the sclerites of the attachment apparatus and details for identifying the $D$. fraternus fauna on the bleak (Alburnus alburnus L.). According to the results obtained, and were encountered on the bleak. The parasite found, from the shape of the copulatory organ and the morphology of the vaginal aperture, and also upon the structure of macro-and micro-hooks, can be considered to be Dactylogyrus fraternus.

\section{Acknowledgements}

We thank Dr. Yildirimhan (Uludag University) for providing and identifying the parasites studied. Dr. Aydogdu was partially supported by a student fellowship from the laboratory facilities.

\section{References}

Baer, J. G. (1957). First symposium on host specificity among parasites of vertebrates. Neuchatel: Paul Attinger.

Bychowsky, B. E. (1957). Monogenic Trematodes, Their Systematics and Phylogeny. Acad. Sci. USSR.

Dupont, F. and A. Lambert (1986). Study of parasitic communities of Monogenea Dactylogyridae from Cyprinidae in lake Mikri Prespa (Northern Greece) description of three species from an endemic Barb: Barbus cyclolepis prespensis Karaman, 1924. Ann. Parasitol. Hum. Carp. 61: 597-616.

Ergens, R., (1988). Four species of the genus Annulotrema Paperna and Thurston, 1969 (Monogenea: Ancyrocephalinae) from Egyptian freshwater fish. Folia Parasitol. 35: 209-215

Gelnar, M., B. Koubkova, H. Plankova and P. Jurajda (1994). Report on metazoan parasites of fishes of the river Morava with remarks on the effects of water pollution. Helminthologia 31:47-56.

Hargis, W J. (1957). The host specificity of monogenetic trematpdes. Exp.Parasitol 6:610-625.

Hayward,C.(2005).MonogeneaPolyopisthocotylea (Ectoparasitic Flukes), pp. 55-63. In: K. Rohde (Eds.) Marine Parasitology. CSIRO Publishing Melburne and CABI Wallingford Oxon.

Lambert, A. (1977). Les Monogenes Monopisthocotylea parasites des poissons d'eau douce de la France méditerranéenne. Bulletin du Muséum National d'Histoire Naturelle 3e Série No. 429, Janvier-Féverier, Zoologie.

Mizelle, J. D. (1936). New species of trematodes from the gills of Illinois fishes. Am. Midl. Nat. 17:785-806.

Noble, E. R., G. A. Chad and A.J. Macinnes, (1989). Parasitology. the biology of animal parasites. $6^{\text {th }}$ Edn. Philadelphia: Lea and Febiger.

Paperna, I. (1979). Monogenea of inland water fish Africa. Annales serie IN 8o Sciences Zoologiques. Museée Royal de 1'Afrique centrale 226:1-131.

Paperna, I. (1963)a. Some observations on the biology of Dactylogyrus vastator in Israel. Bamidgeh. Bull. Fish Cult. Israel 15: 8-28.

Paperna, I. (1963)b. Dynamics of Dactylogyrus vastator Nybelin (Monogenea) populations on the gills of carp fry in fish ponds. Bamidgeh. Bull. Fish Cult. Israel 15:31-50.

Park, J. K., K. H. Kim, S. Kang, W. Kim, K. S. Eom and D. T. J. Littlewood (2007). A common origin of complex life cycles in parasitic flatworms: evidence from the complete mitochondrial genome of Microcotyle sebastis (Monogenea: Platyhelminthes) BMC Evolutionary Biology 7:11.

Reichenbach-Klinke, H. H. (1973). Fish Pathology, T.F.H. Publications, Inc. Neptune City, NJ.

Rohde, K. (1979). A critical evaluation of intrinsic and extrinsic factors responsible for niche restriction in parasites. American Naturalist 114: 648-671.

Rohde, K., N. Watson, and F. Roubal (1989). Ultrastructure of the protonephridial system of Dactylogyrus sp. and an unidentified ancyrocephaline (Monogenea: Dactylogyridae). International Journal for Parasitology 19:859-864.

Sasal, P., Y. Desdevises and S. Morand (1998). Hostspecialization and species diversity in fish parasites: phylogenetic conservatism. Ecography 21:639-645.

Whittington, I. D. (2005). Monogenea Polyopisthocotylea (Ectoparasitic Flukes), 63-72 pp. In: Rohde K. (Eds.). Marine Parasitology. CSIRO Publishing Melburne and CABI Wallingford Oxon. 